\title{
First record of Dendrocerus carpenteri (Hymenoptera: Megaspilidae) on Aphidius ervi in alfalfa fields in Brazil
}

\author{
L. G. R. Iemma ${ }^{a *}$, M. T. Tavares ${ }^{b}$ and C. R. Sousa-Silva \\ ${ }^{a}$ Laboratório de Entomologia Aplicada - LEA, Programa de Pós-graduação em Ecologia e Recursos \\ Naturais, Departamento de Ecologia e Biologia Evolutiva, Universidade Federal de São Carlos - UFSCar, \\ Rodovia Washington Luis, Km 235, s/n, CP 676, CEP 13565-905, São Carlos, SP, Brazil \\ baboratório de Biodiversidade de Insetos - LABI, Departamento de Ciências Biológicas, \\ Universidade Federal do Espírito Santo - UFES, Av. Marechal Campos, 1468, \\ CEP 29040-090, Vitória, ES, Brazil \\ 'Laboratório de Entomologia Aplicada - LEA, Departamento de Ecologia e Biologia Evolutiva, \\ Universidade Federal de São Carlos - UFSCar, Rodovia Washington Luis, Km 235, s/n, CP 676, \\ CEP 13565-905, São Carlos, SP, Brazil \\ *e-mail: luis_iemma@yahoo.com.br
}

Received: May 4, 2015 - Accepted: November 22, 2015 - Distributed: November 30, 2016

(With 3 figures)

The Megaspilidae is a small Hymenopteran family with 12 genera in two subfamilies, and 450 known species, with a large amount of species still undescribed. This group is poorly known as a whole, though most are believed to be parasitoids (especially of Sternorrhynchan Hemiptera), and a few being hyperparasitoids (Alekseev, 1987). The remarkably diverse host range of Dendrocerus seems to be centred around predators and parasitoids of Hemiptera Sternorrhyncha (Fergusson, 1980).

Dendrocerus carpenteri was obtained from the primary parasitoid Aphidius ervi in Acyrthosiphon pisum host collected in alfalfa (Medicago sativa) in "Embrapa Pecuária Sudeste", located in São Carlos - SP and individually separated into Eppendorf microtubes $(1.5 \mathrm{~mL})$. In the laboratory, they were allocated in a room with temperature around 25 degrees. After emergence, adult hyperparasitoids were transferred to a freezer and afterwards it was identified. The Aphid was identified by the last author. Dendrocerus carpenteri was identified by the first author, using Noyes (1980) and Johnson and Musetti's (2004). The specimens were studied under a Leica M125 stereomicroscope with a 16x ocular, Images were captured using an automated Z16 Leica system and DFG495 Leica Digital camera.

During the sampling period, thirty two specimens of Dendrocerus carpenteri were reared from the primary parasitoid Aphidius ervi on the host Acyrthosiphon pisum, collected on the host plant Medicago sativa.

Dendrocerus carpenteri is known by having a particularly shorter scape (at most 5 times as long as broad) (Figure 1). Notaulices only slightly convergent, not meeting median furrow, or if they meet or almost meet then they converge in curve (Figure 2). Pterostigma approximately semicircular (Figure 3), radius deeply angled. It is a widespread species on a wide range of aphids and plants. Tavares (1996) already have described its occurrence in other cultures in Brazil, but this is the first occurrence in alfalfa fields in Brazil.
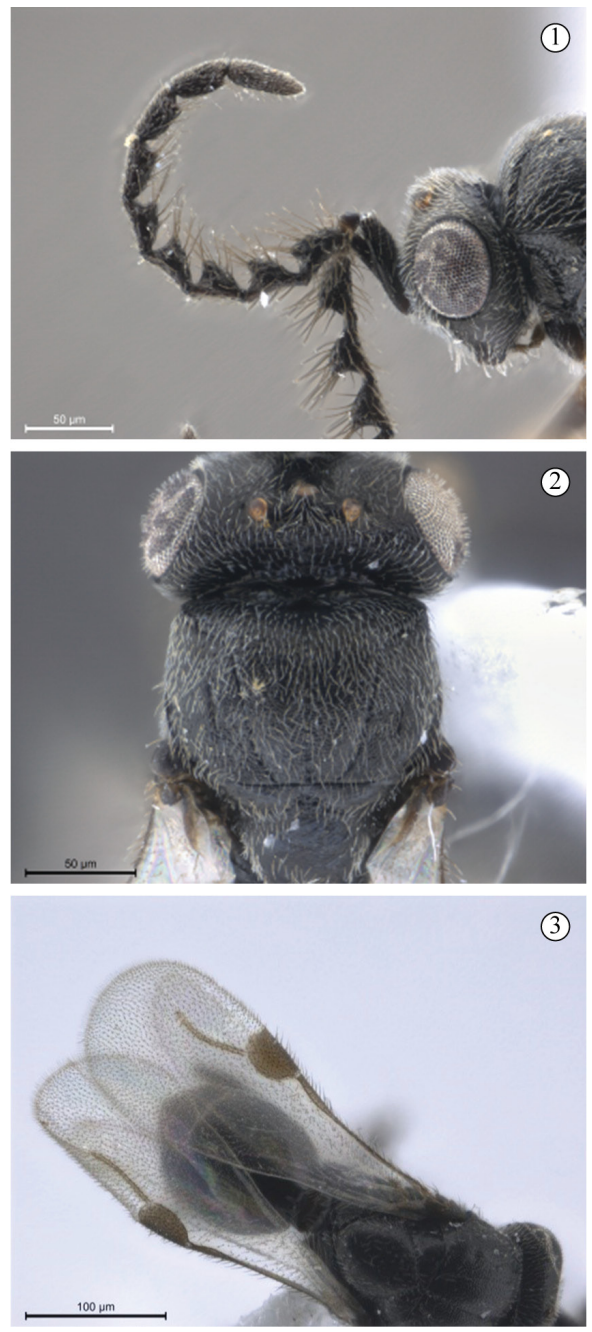

Figures 1-3. Dendrocerus carpenteri (1 - Antennae; 2 - Notaulices; 3 - Pterostigma). 


\section{Acknowledgements}

We thank "Coordenação de Aperfeiçoamento de Pessoal de Nível Superior" (CAPES) for the financial support.

\section{References}

ALEKSEEV, V.N., 1987. Family Megaspilidae (Megaspilids). In: G.S. MEDVEDEV, ed. Keys to the insects of the European part of the USSR. New Delhi: Amerind Publishing, vol. 3. 1341 p. Hymenoptera, Pt. 2.

FERGUSSON, N.M.D., 1980. A revision of the british species of Dendrocerus Ratzeburg (Hymenoptera, Ceraphronoidea) with a review of their biology as aphid hyperparasites. Bulletin of the British Museum (Natural History): Historical Series, vol. 41, pp. 255-314. http://dx.doi.org/10.5962/bhl.part.28549.

JOHNSON, N.F. and MUSETTI, L., 2004. Catalog of systematic literature of the superfamily Ceraphronoidea Hymenoptera). Contributions of the American Entomological Institute, vol. 33, pp. 1-149.

NOYES, J.S., 1980. A review of the genera of Neotropical Encyrtidae (Hymenoptera: Chalcidoidea). Bulletin of the British Museum (Natural History): Historical Series, vol. 41, pp. 107-253.

TAVARES, M.T., 1996. Ocorrência de Dendrocerus carpenteri (Curtis) (Hymenoptera: Megaspilidae) no Brasil. Anais da Sociedade Entomológica do Brasil, vol. 25, no. 2, pp. 363-364. 